1 Supporting Information

2 Role of pyrogenic carbon in parallel microbial

3 reduction of nitrobenzene in the liquid and

4 sorbed phases

Hefei Wang ${ }^{a, b}$, He-Ping Zhao ${ }^{a}$, Lizhong Zhu ${ }^{a, b}$,

6

7

8

9

*Corresponding Author: Prof. Lizhong Zhu, a. College of Environmental and Resource Sciences, Zhejiang University, Hangzhou 310058, China; b. Key

Laboratory of organic pollution process and control, Zhejiang Province, Zhejiang

University, Hangzhou 310058, China; E-mail: zlz@,zju.edu.cn

a. College of Environmental and Resource Science, Zhejiang University, Hangzhou 310058, China;

b. Key Laboratory of organic pollution process and control, Zhejiang province, Zhejiang University, Hangzhou 310058, China.

This supplementary material contains 20 pages, including 2 test, 2 table and 12 figures. 


\section{Legend of contents}

Text S1. Chemicals

Text S2. Methods for deducing the reduction rate

Table S1. Characterization results of pyrolysis carbon.

Table S2. Sorption-desorption and reduction constants obtained in this study.

Table R3 Contribution of nitrobenzene reduction in the aqueous phase and sorbed phase.

Figure S1. Fourier transform infrared (FTIR) spectroscopy of pyrogenic carbon produced at pyrolysis temperature $250-900{ }^{\circ} \mathrm{C}$.

Figure S2. ${ }^{13} \mathrm{C}$ NMR spectroscopy of pyrogenic carbons (produced at pyrolysis temperature 350 and $500{ }^{\circ} \mathrm{C}$ ) before and after oxidizing with $\mathrm{HNO}_{3}$.

Figure S3. Plot of electrical resistances of pyrogenic carbons produced at pyrolysis temperature $250-900{ }^{\circ} \mathrm{C}$ with pressure.

Figure S4. Concentration of NB in solution and extracted from pyrogenic carbon after $1 \mathrm{~g} \mathrm{~L}^{-1}$ pyrogenic carbon was added to synthesized medium containing $100 \mathrm{mg}$ $\mathrm{L}^{-1} \mathrm{NB}$ and equilibrated for $48 \mathrm{~h}$.

Figure S5. N recoveries during the reduction of nitrobenzene by S. oneidensis MR-1 in the absence and presence of pyrogenic carbon.

Figure S6. Degradation of nitrobenzene in liquid and sorbed phase in the sample with

BC500 and S. oneidensis MR-1.

Figure S7. Concentration of L-sodium lactate within the reduction time. 
Figure S8. Isolated reduction of sorbed nitrobenzene onto BC700 by S. oneidensis

MR-1

Figure S9. Simultaneous reductions of nitrobenzene in liquid (a) and solid phases (b) in the presence of $\mathrm{BC} 500, p$-benzoquinone ( $p$-DQN) modified BC500, and 9,10-anthracenequinone (9, 10-EQN) modified BC500.

Figure S10. Microbial reductions of nitrobenzene in solid phases in the presence of BC500, 500-N-1, 500-N-3, and 500-N-5.

Figure S11. Correlation between the aqueous reduction rate constants $\left(k_{\mathrm{aq}}\right)$ for samples containing $\mathrm{HNO}_{3}$-oxidized $\mathrm{BC} 500$ and contents of oxygenated functional groups.

Figure S12. Microbial reduction of nitrobenzene sorbed on pyrogenic carbon produced at temperatures of $500-900{ }^{\circ} \mathrm{C}$ 


\section{Text S1}

57

58

59

60

61

62

63

64

65

66

67

68

69

70

\section{Chemicals}

Nitrobenzene Standard (GC grade), DL-sodium lactate (AR, $60 \%$ in water), p-benzoquinone ( $\geq 99 \%$ ), 9,10-anthracenequinone ( $\geq 98 \%$ ), HEPES ( $\geq 99.9 \%$ ), acetonitrile and methanol (HPLC grade) were purchase from Aladdin Biochemical Technology Co. LTD. Yeast extract (for microbial culture), peptone (for microbial culture) were obtained from Sangon Biotech (Shanghai) Co., Ltd. $66 \% \mathrm{HNO}_{3}$ was acquired from Sinopharm Chemical Reagent Co., Ltd. 2,2'azino-bis(3-ethylbenzothiazoline-6-sulfonic acid) diammonium salt (ABTS, $\geq 98 \%$ ) was purchased from Sigma-Aldrich biochemical reagent Co. LTD and zwitterionic viologen 4,4'-bipyridinium-1,1'-bis(2-ethylsulfonate) (ZiV) was synthesized as detailed elsewhere. ${ }^{42}$ All other solvents and reagents used were of HPLC grade and analytical grade. Deionized water $(18 \mathrm{M} \Omega)$ was produced with a Pall Cascada I water purification system. 


\section{Text S2}

\section{Methods for deducing the reduction rate}

Sorption and desorption rate of nitrobenzene on pyrogenic carbon was also measured in the absence of $S$. oneidensis MR-1. Concentration of nitrobenzene in aqueous phase can be described in Langmuir Kinetic mode ${ }^{39}$ :

$$
\frac{d C}{d t}=-k_{\mathrm{a}}\left(Q_{\mathrm{e}}-Q\right) \rho C+k_{\mathrm{d}} Q
$$

where $k_{\mathrm{a}}$ is the sorption rate constant $\left(\mathrm{mM}^{-1} \cdot \mathrm{s}^{-1}\right), Q_{\mathrm{e}}$ is the maximum absorption capacity $\left(\mathrm{mmoles} \cdot \mathrm{g}^{-1}\right), \rho$ is the concentration of pyrogenic carbon $\left(1 \mathrm{~g} \cdot \mathrm{L}^{-1}\right), C$ is the aqueous concentration $(\mathrm{mM}), k_{\mathrm{d}}$ is the desorption rate constant $\left(\mathrm{s}^{-1}\right),\left(Q_{\mathrm{e}}-Q\right)$ represents the concentration of vacant sorption sites. To get $Q_{\mathrm{e}}$, a series of concentration of nitrobenzene from 0.5 to $17.9 \mathrm{mM}$ was used for equilibration with $1.0 \mathrm{~g} \cdot \mathrm{L}^{-1}$ pyrogenic carbon. $Q_{\mathrm{e}}$ for $\mathrm{BC} 500, \mathrm{BC} 700$, and $\mathrm{BC} 900$ was determined as 0.96, 1.35 , and $3.71 \mathrm{mmoles} \cdot \mathrm{g}^{-1}$ respectively. $C$ and $Q$ have the relationship as follow:

$$
Q=\frac{N-C \mathrm{~V}}{m}
$$

where $N$ is the initial dosage of nitrobenzene (mmole), $m$ is the pyrogenic carbon usage $(\mathrm{g})$, and $\mathrm{V}$ is the volume of liquid (L).

To get $k_{\mathrm{a}}$ and $k_{\mathrm{d}}$, we investigated the sorption kinetics of nitrobenzene on pyrogenic carbon. Initial concentration of nitrobenzene was $100 \mathrm{mg} \cdot \mathrm{L}^{-1}(0.81 \mathrm{mM})$ and pyrogenic carbon was $1 \mathrm{~g} \cdot \mathrm{L}^{-1}$. The maximum sorbed nitrobenzene $(Q)$ was remarkably smaller than $Q_{\mathrm{e}}$ (e.g. $0.75 \mathrm{mmoles} \cdot \mathrm{g}^{-1}$ for BC900). Accordingly, equation (2) can be written as (3),

$$
\frac{d C}{d t}=-\rho\left(k_{\mathrm{a}} Q_{\mathrm{e}}+\frac{\mathrm{V}}{m} k_{\mathrm{d}}\right) C+\rho_{m}^{N k_{\mathrm{d}}}
$$


93 Letting $\lambda=\rho_{m}^{N k_{\mathrm{d}}}, \gamma=\rho\left(Q_{\mathrm{e}} k_{\mathrm{a}}+\frac{\mathrm{V}}{m} k_{\mathrm{d}}\right)$ and solving differential equation (3), we get

$94 \quad C=\frac{\lambda}{\gamma}+\mathrm{U} e^{-\gamma t}$

$95 k_{\mathrm{a}}$ and $k_{\mathrm{d}}$ were obtained by a non-linearly fitting of the measured nitrobenzene

96

97

concentrations in liquid phase to equation (4). When S. oneidensis MR-1 cells were added, the aqueous concentration $C$ and sorption $Q$ of nitrobenzene on pyrogenic carbon was described using equation (5) and (6):

$$
\begin{aligned}
& \frac{d C}{d t}=-k_{\mathrm{a}}\left(Q_{\mathrm{e}}-Q\right) \rho C+k_{\mathrm{d}} \rho Q-k_{\mathrm{aq}} C \\
& \frac{d \mathrm{Q}}{d t}=k_{\mathrm{a}}\left(Q_{\mathrm{e}}-Q\right) C-k_{\mathrm{d}} Q-k_{\mathrm{ad}} Q
\end{aligned}
$$

where $k_{\mathrm{aq}}$ and $k_{\mathrm{sd}}$ are the aqueous and sorbed nitrobenzene reduction rate constants, respectively. $k_{\mathrm{aq}} C$ and $k_{\mathrm{sd}} Q$ represent the reaction term and others are sorption/desorption term. $k_{\mathrm{aq}}$ and $k_{\mathrm{sd}}$ were determined by fitting the aqueous and sorbed concentration $C$ and $Q$ using the Kintecus Modeling software.

To quantify the contribution of degradation in aqueous phase and sorbed phase, we calculated the aqueous nitrobenzene reduction term $\left(R_{\mathrm{aq}}\right)$ and sorbed nitrobenzene reduction term $\left(R_{\mathrm{sd}}\right) . R_{\mathrm{aq}}$ was given in the following equation:

$$
R_{\mathrm{aq}}=\int k_{\mathrm{aq}} C+k_{\mathrm{d}} \rho Q d t
$$

$R_{\mathrm{sd}}$ was described in the following equation:

$$
R_{\mathrm{sd}}=\int k_{\mathrm{sd}} \mathrm{Q} \mathrm{dt}
$$

Contribution of reduction in aqueous phase and sorbed phase is shown in Table S3. 
115 Table S1 Characterization results of pyrogenic carbon.

\begin{tabular}{|c|c|c|c|c|c|c|c|}
\hline \multirow{2}{*}{ sample } & \multicolumn{3}{|c|}{ percentage by weight } & \multirow{2}{*}{$\begin{array}{l}\text { molar } \\
\mathrm{H} / \mathrm{C}\end{array}$} & \multirow{2}{*}{$\begin{array}{l}\text { molar } \\
\mathrm{O} / \mathrm{C}\end{array}$} & \multirow{2}{*}{$\begin{array}{l}\text { surface area } \\
\qquad\left(\mathrm{m}^{2} \cdot \mathrm{g}^{-1}\right)\end{array}$} & \multirow{2}{*}{$\begin{array}{l}\text { conductivity } \\
\qquad\left(\mathrm{S} \cdot \mathrm{cm}^{-1}\right)\end{array}$} \\
\hline & $\mathrm{C}$ & $\mathrm{H}$ & $\mathrm{O}$ & & & & \\
\hline BC250 & 63.34 & 7.53 & 27.53 & 1.43 & 0.47 & 127.76 & 0.00 \\
\hline BC 350 & 74.32 & 5.81 & 17.88 & 0.94 & 0.27 & 147.61 & 0.00 \\
\hline BC500 & 81.45 & 3.71 & 13.00 & 0.55 & 0.16 & 137.40 & 0.00 \\
\hline BC600 & 82.68 & 2.82 & 13.23 & 0.41 & 0.12 & 164.23 & 0.00 \\
\hline ВC650 & 84.12 & 2.45 & 11.22 & 0.35 & 0.10 & 177.51 & 0.02 \\
\hline BC700 & 85.86 & 2.20 & 10.30 & 0.31 & 0.09 & 183.02 & 0.13 \\
\hline BC 800 & 87.53 & 1.39 & 9.34 & 0.19 & 0.08 & 123.18 & 4.23 \\
\hline BC900 & 88.17 & 0.99 & 9.40 & 0.13 & 0.08 & 66.76 & 4.85 \\
\hline $500-\mathrm{N}-1$ & 74.64 & 2.86 & 18.17 & 0.46 & 0.18 & 149.11 & 0.00 \\
\hline $500-\mathrm{N}-3$ & 64.96 & 3.76 & 25.88 & 0.69 & 0.29 & 166.71 & 0.00 \\
\hline $500-N-5$ & 65.32 & 3.76 & 25.74 & 0.69 & 0.30 & 179.91 & 0.00 \\
\hline
\end{tabular}


119 Table S2 Sorption-desorption and reduction rate constants obtained in this study.

\begin{tabular}{ccccc}
\hline Sample & $k_{\mathrm{a}}\left(\mathrm{mM}^{-1} \cdot \mathrm{h}^{-1}\right)$ & $k_{\mathrm{d}}\left(\mathrm{h}^{-1}\right)$ & $k_{\mathrm{aq}}\left(\mathrm{h}^{-1}\right)$ & $k_{\mathrm{sd}}\left(\mathrm{h}^{-1}\right)$ \\
\hline BC500 & 0.010 & 0.011 & 0.032 & 0.003 \\
BC700 & 0.011 & 0.008 & 0.037 & 0.009 \\
BC900 & 0.033 & 0.012 & 0.038 & 0.013 \\
\hline
\end{tabular}

120 
Table R3 Contribution of nitrobenzene reduction in the aqueous phase $\left(R_{\mathrm{aq}}\right)$ and 122 sorbed phase $\left(R_{\mathrm{sd}}\right)$.

\begin{tabular}{ccc}
\hline sample & $R_{\mathrm{aq}}(\mathrm{mM})$ & $R_{\mathrm{sd}}(\mathrm{mM})$ \\
\hline BC500 & 0.59 & 0.08 \\
BC700 & 0.53 & 0.31 \\
BC900 & 0.43 & 0.59 \\
\hline
\end{tabular}

123 
124

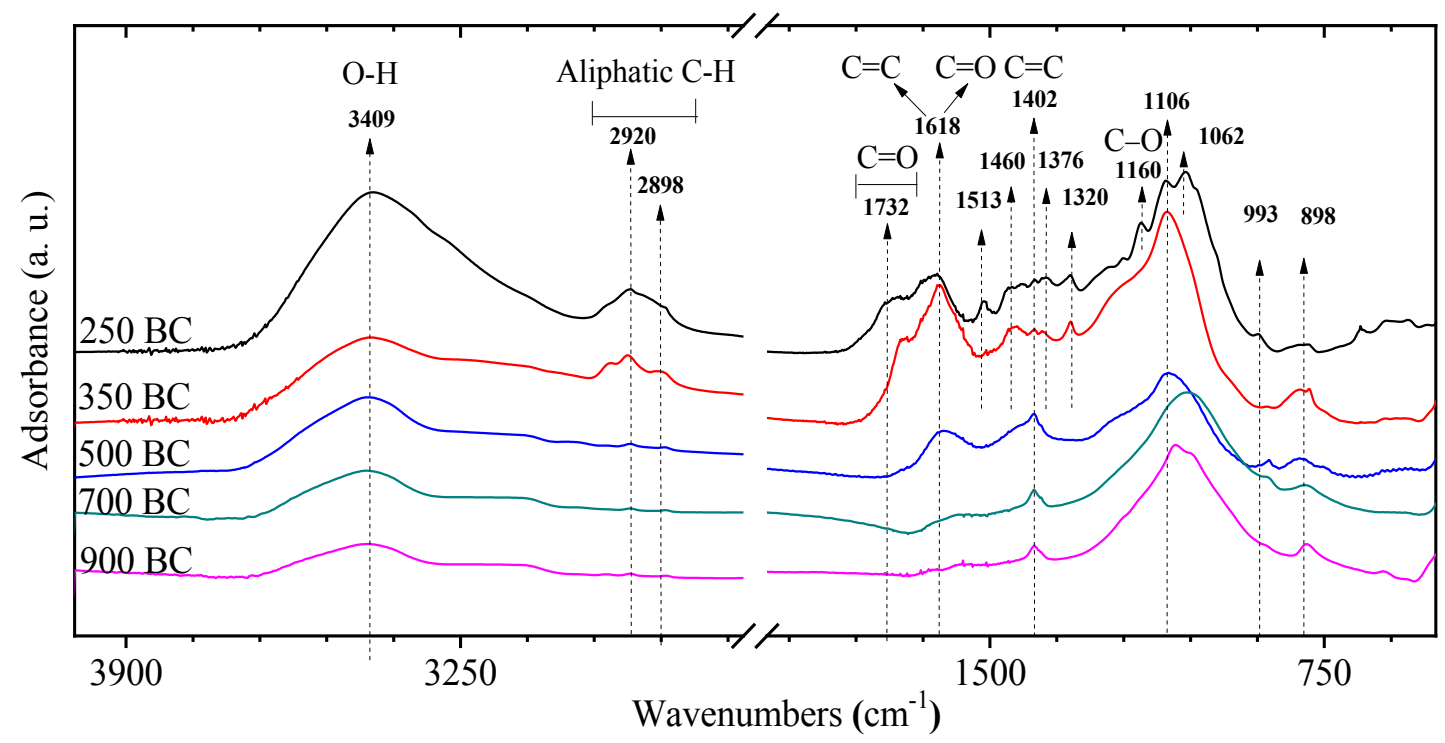

126 Figure S1. Fourier transform infrared (FTIR) spectroscopy of pyrogenic carbon

127 produced at pyrolysis temperature $250-900{ }^{\circ} \mathrm{C}$.

128 


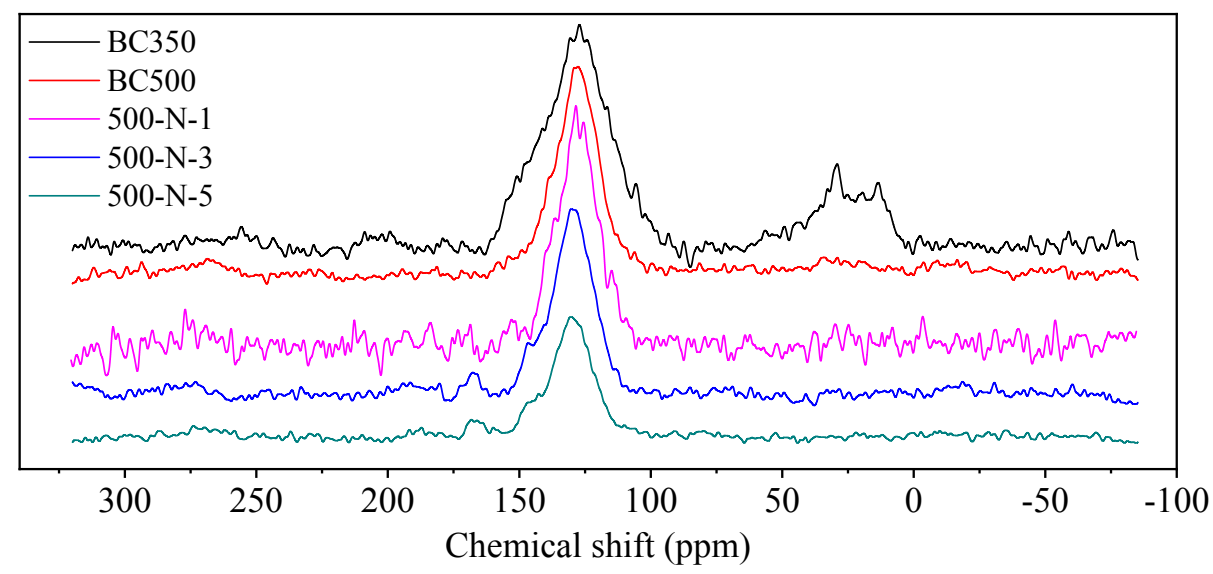

130

131 Figure S2. ${ }^{13} \mathrm{C}$ NMR spectroscopy of pyrogenic carbons (produced at pyrolysis temperature 350 and $500{ }^{\circ} \mathrm{C}$ ) before and after oxidizing with $\mathrm{HNO}_{3}$. Peak areas of $\mathrm{COOH}, \mathrm{C}=\mathrm{O}, \mathrm{C}-\mathrm{OH}$ and aliphatic $\mathrm{C}$ decreased insignificantly with the increase of pyrolysis temperature from 350 to $500{ }^{\circ} \mathrm{C}$. While peak area of $\mathrm{COOH}$ and $\mathrm{C}=\mathrm{O}$ greatly rose after oxidation with $\mathrm{HNO}_{3}$. NMR spectroscopy of pyrogenic carbons produced at pyrolysis temperature $>500{ }^{\circ} \mathrm{C}$ was not shown because of the similar peak position and peak areas with $\mathrm{BC} 500$. The contents of $\mathrm{COOH}$ and $\mathrm{C}=\mathrm{O}$ was

138 similar to the results from previous study. ${ }^{20,29}$ 

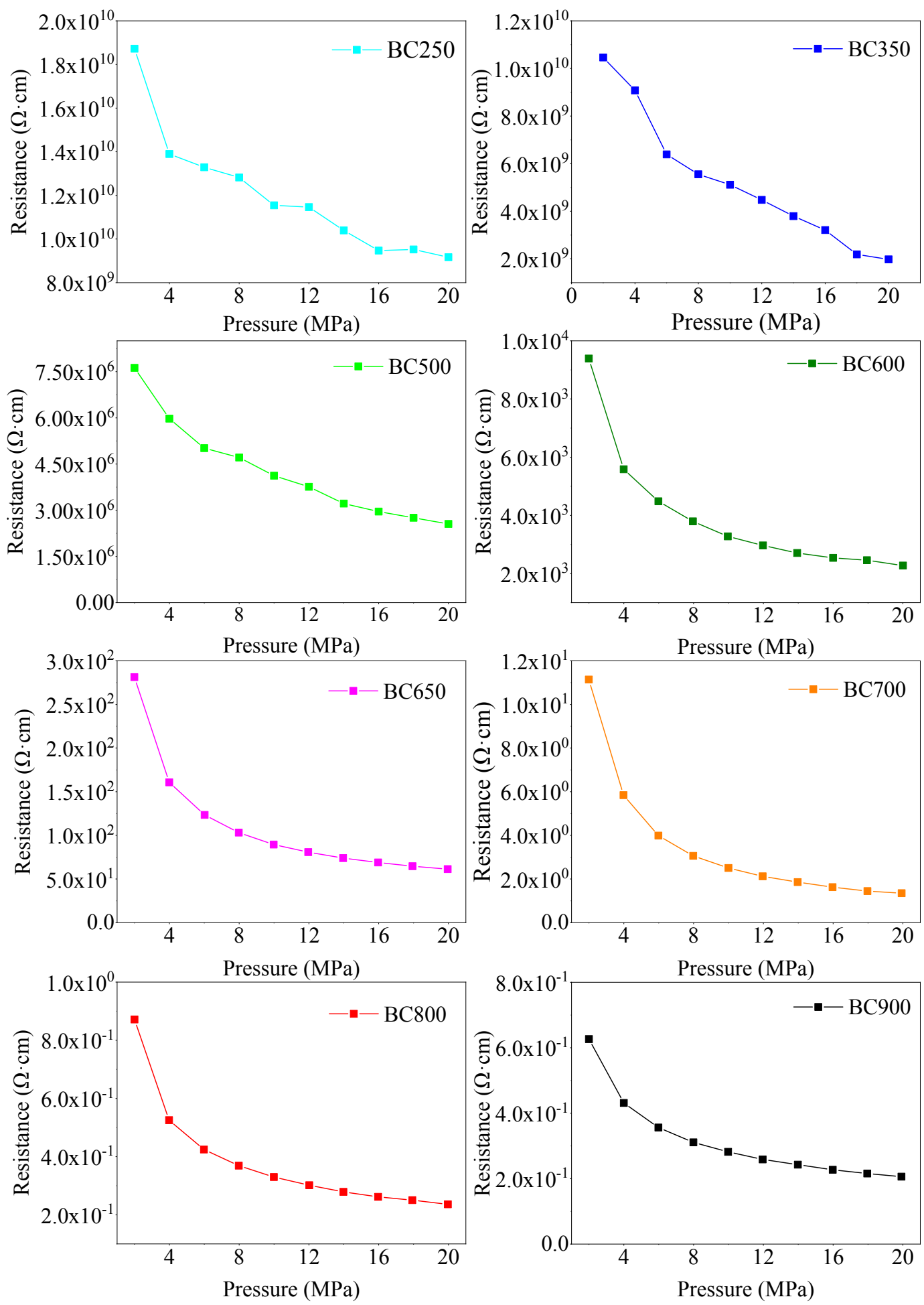

Figure S3. Plot of electrical resistances of pyrogenic carbons produced at pyrolysis temperature $250-900{ }^{\circ} \mathrm{C}$ with pressure. Resistance at pressure of $20 \mathrm{MPa}$ was used for

143 calculating electrical conductivity. The detailed method to measure resistance of

144 pyrogenic carbon was reported by Mochidzuki et al. ${ }^{41}$ 


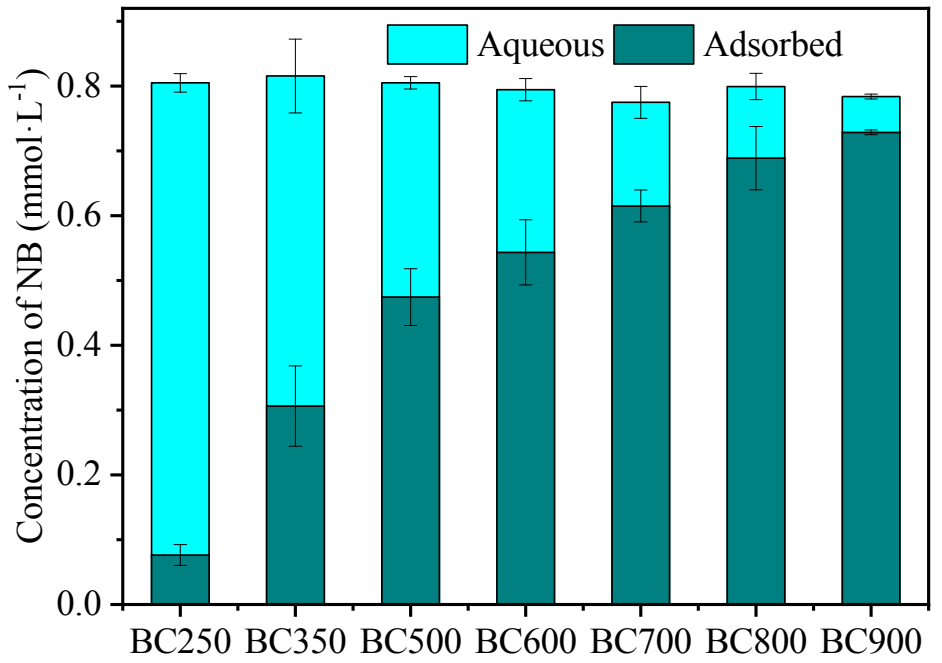

146 Figure S4. Concentration of NB in solution and extracted from pyrogenic carbon

147 after $1 \mathrm{~g} \mathrm{~L}^{-1}$ pyrogenic carbon was added to synthesized medium containing $100 \mathrm{mg}$ $148 \quad \mathrm{~L}^{-1} \mathrm{NB}$ and equilibrated for $48 \mathrm{~h}$.

149 


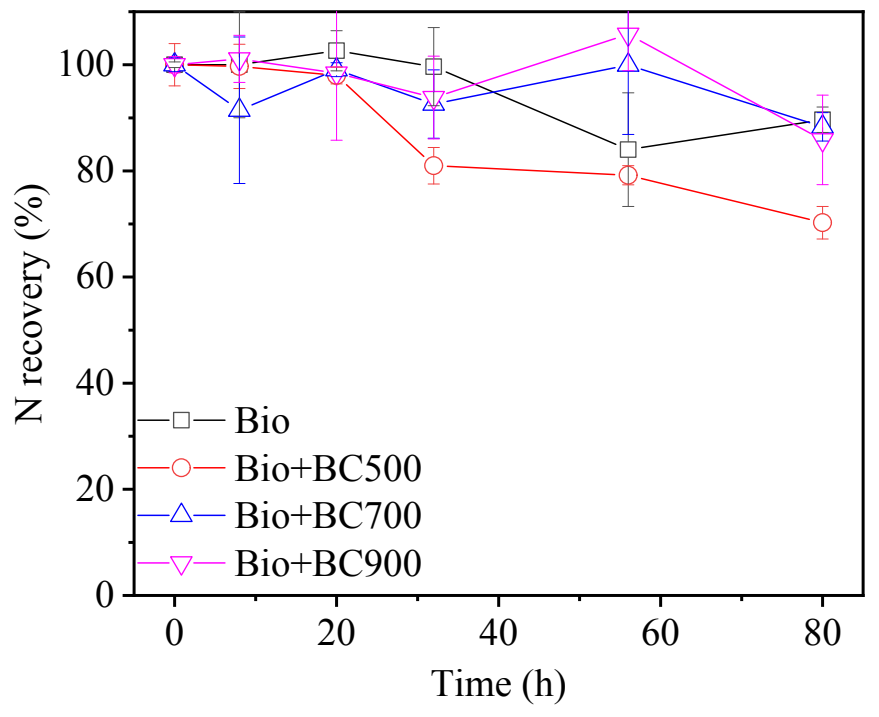

151 Figure S5. N recoveries during the reduction of nitrobenzene by $S$. oneidensis MR-1

152 in the absence and presence of pyrogenic carbon.

153 


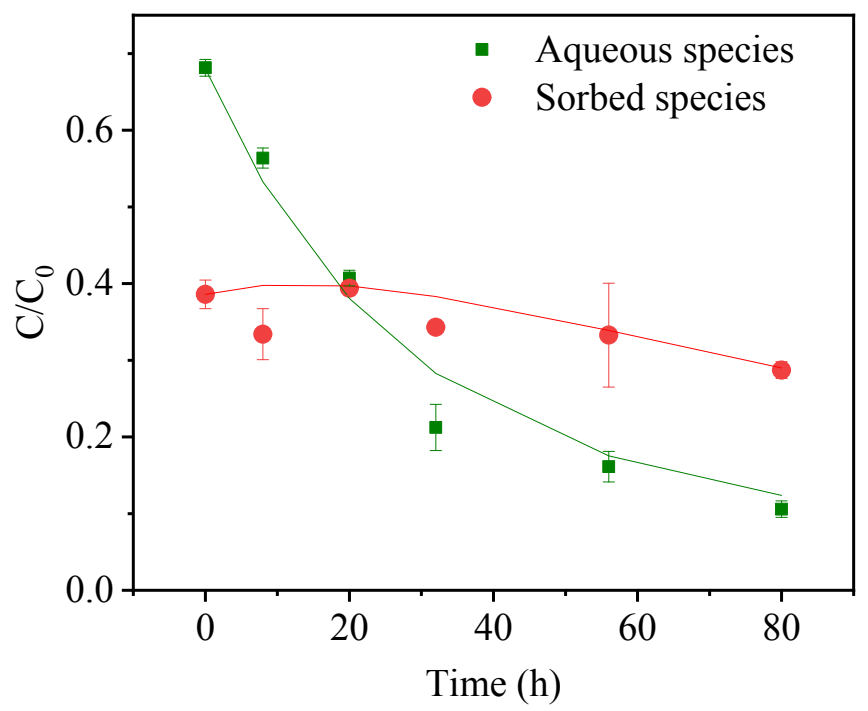

155

156

157

158

159

160

Figure S6 Degradation of nitrobenzene in liquid and sorbed phase in the sample with BC500 and S. oneidensis MR-1. (Line was fitted results based on the kinetic model.) 


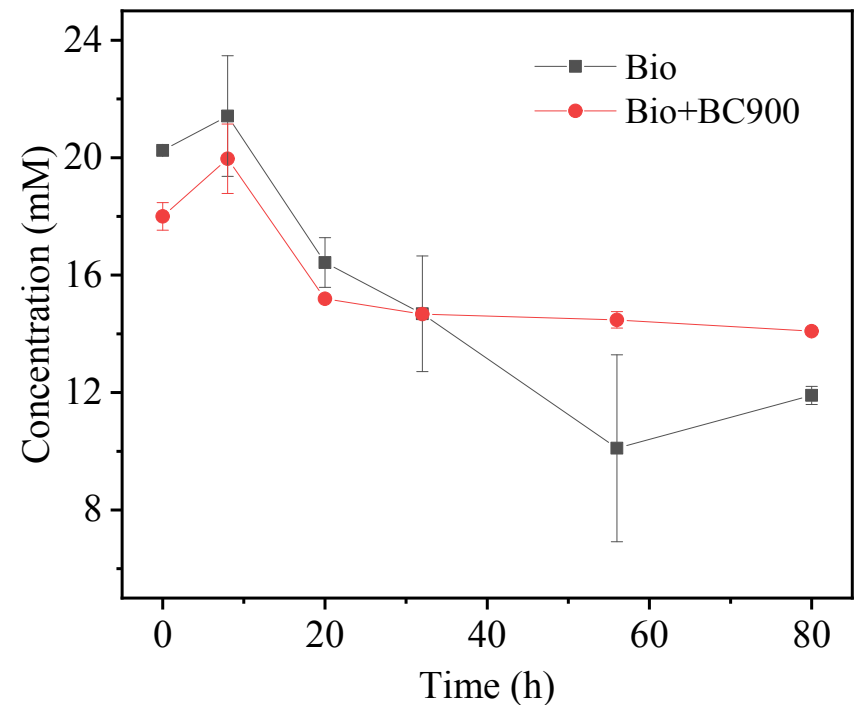

Figure S7. Concentration of L-sodium lactate within the reduction time. 


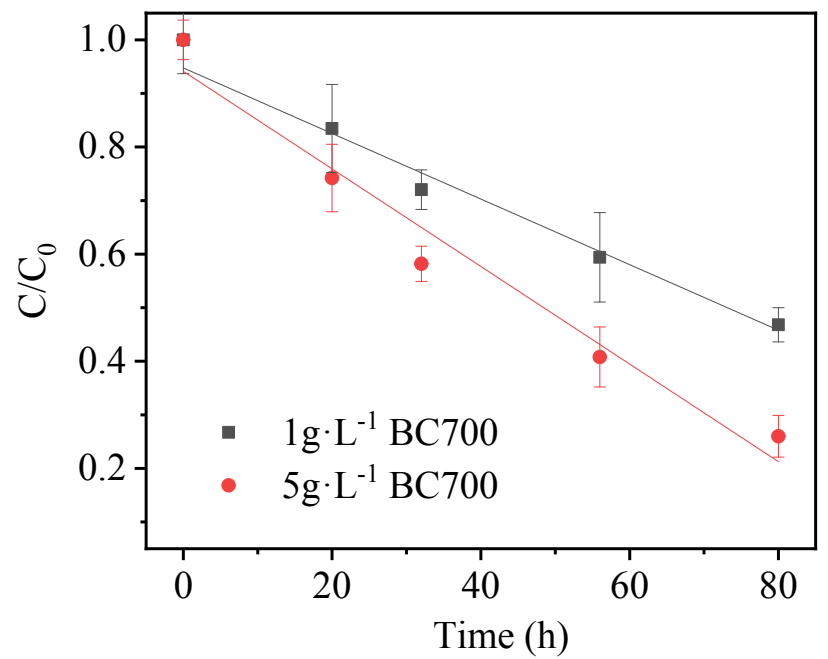

Figure S8. Isolated reduction of sorbed nitrobenzene onto BC700 by S. oneidensis 
(b)

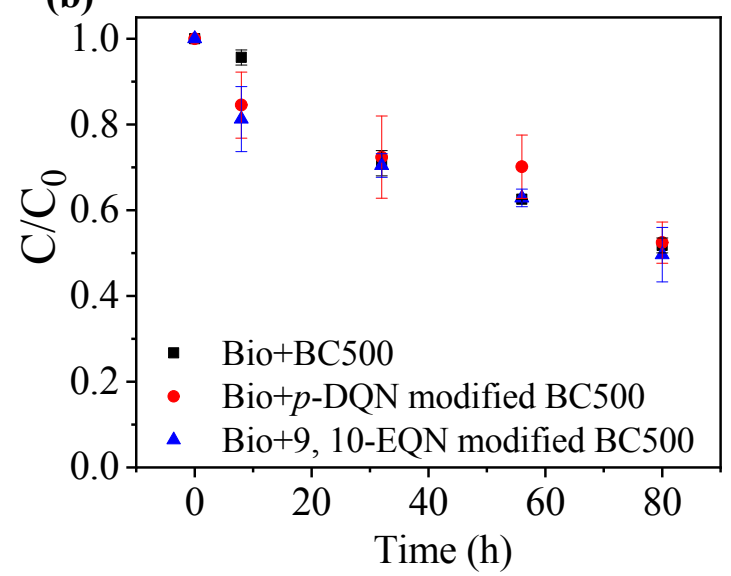

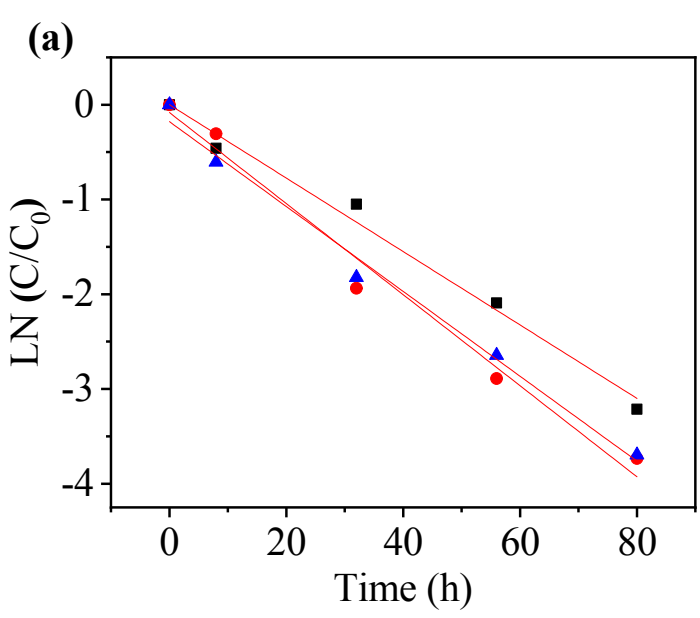

(a)

171

172 Figure S9. Simultaneous reductions of nitrobenzene in liquid (a) and solid phases (b)

173 in the presence of $\mathrm{BC} 500, p$-benzoquinone ( $p$-DQN) modified $\mathrm{BC} 500$, and

1749,10 -anthracenequinone (9, 10-EQN) modified BC500. No obvious enhancement was

175 observed after BC500 was modified by model quinone compound sorption.

176 


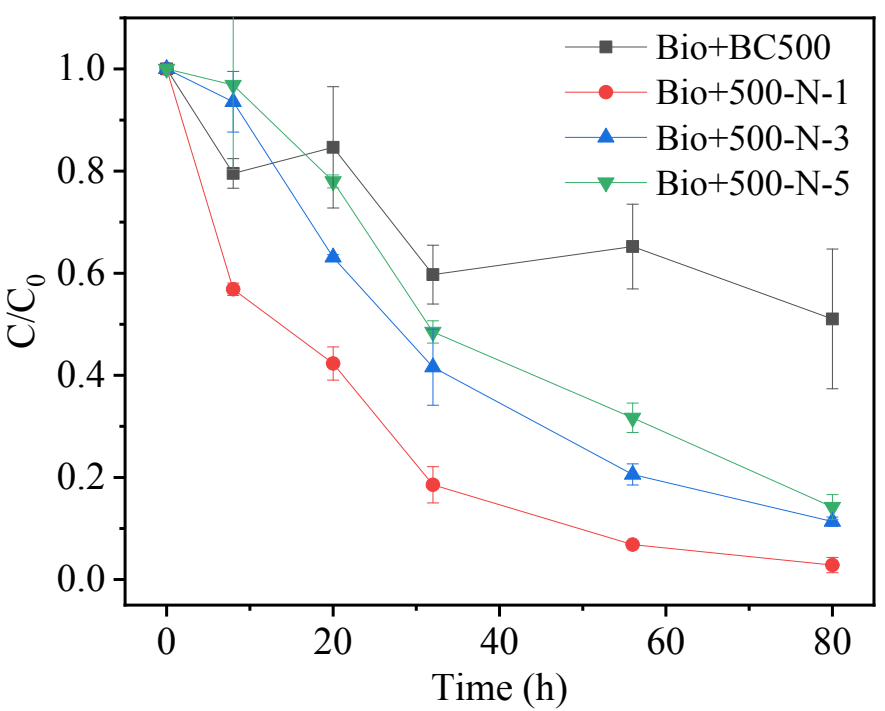

177

178 Figure S10. Microbial reductions of nitrobenzene in solid phases in the presence of

179 BC500, 500-N-1, 500-N-3, and 500-N-5. The initial concentration of nitrobenzene

180 was $100 \mathrm{mg} \mathrm{L}^{-1}$, and only 3.6-21.8 \% was sorbed onto $\mathrm{HNO}_{3}$-oxidized pyrogenic

181 carbon. The observed reduction rate constants $\left(k_{\mathrm{obs}}\right)$ for samples containing $500-\mathrm{N}-3$

182 and $500-\mathrm{N}-5$ were smaller than that for $500-\mathrm{N}-1$ probably because of the lower

183 concentration of nitrobenzene sorbed onto $500-\mathrm{N}-3$ and $500-\mathrm{N}-5$ compared with $184500-\mathrm{N}-1$.

185 

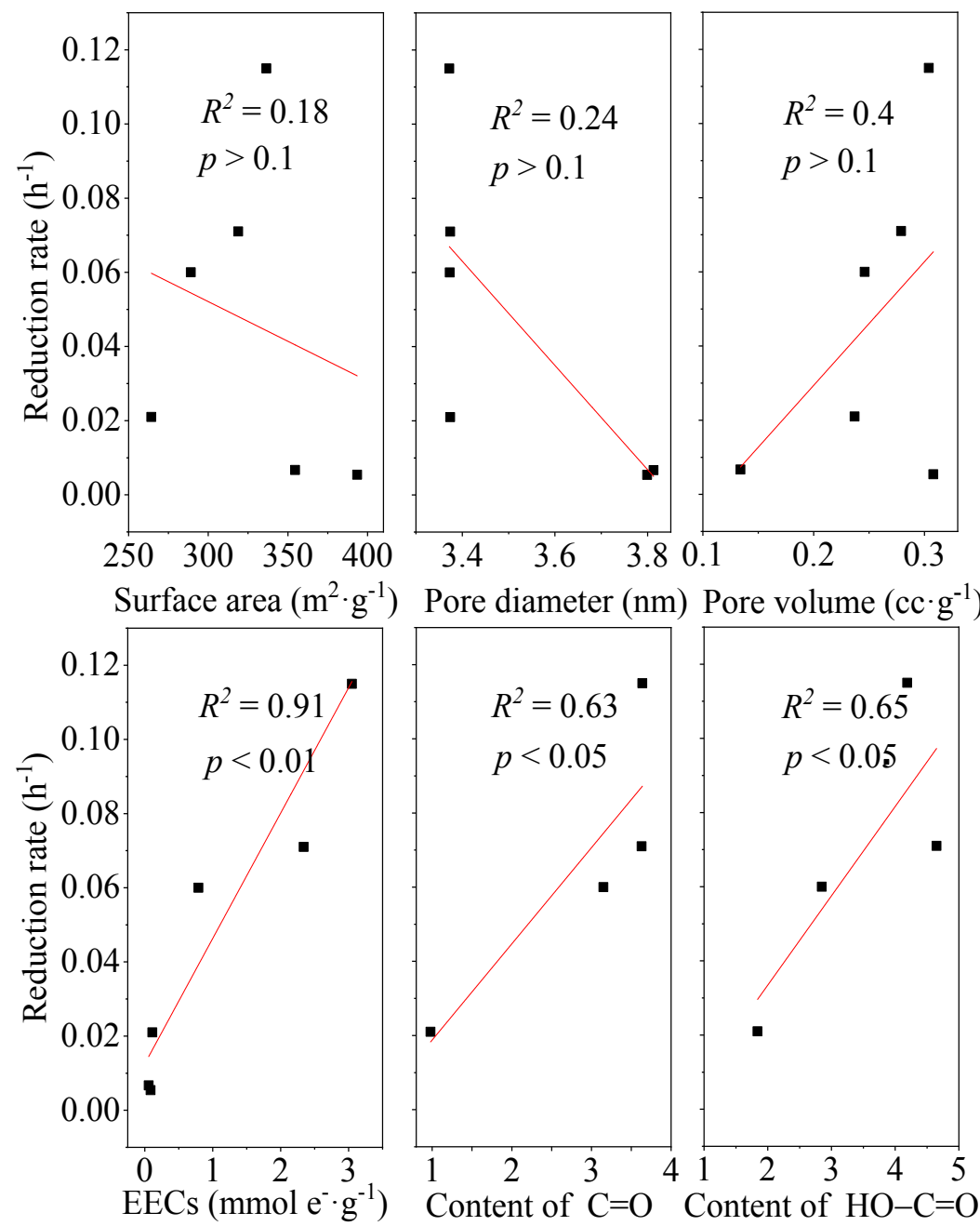

Figure S11. Correlation of the integrated reduction rate constants with properties of

188 pyrogenic carbon including surface area, pore diameter, pore volume, EECs and

189 contents of oxygenated functional groups. Correlation was analysed by the software

190 IBM SPSS Statistics 20. The integrated reduction rate constant was positively linear

191 correlated with the contents of carbonyl and carboxylic groups. 


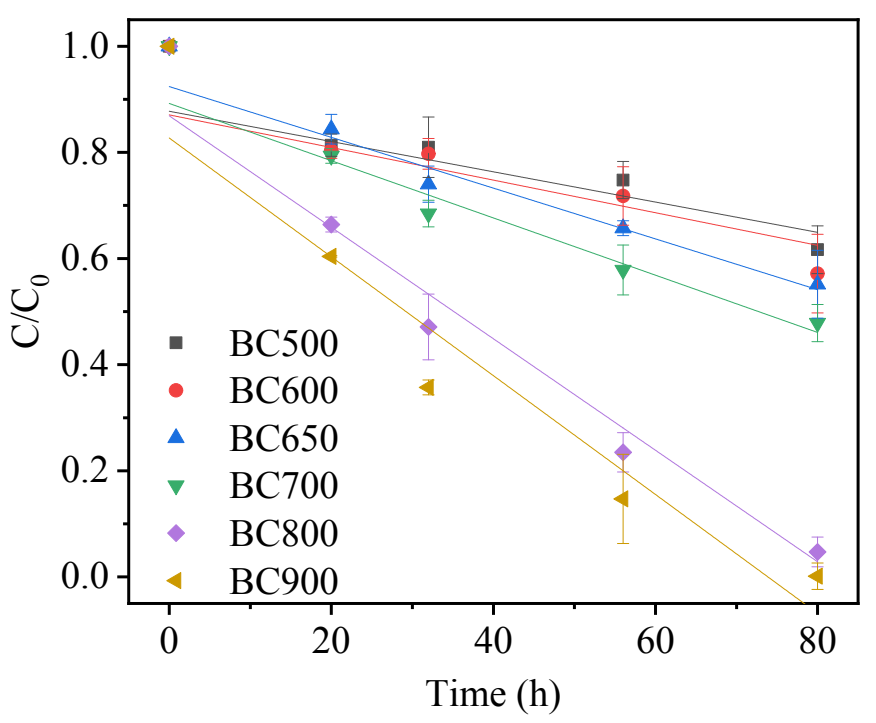

195 Figure S12. Microbial reduction of nitrobenzene sorbed on pyrogenic carbon 196 produced at temperatures of $500-900{ }^{\circ} \mathrm{C}$. Initial concentration of nitrobenzene and 197 pyrogenic carbon was $40 \mathrm{mg} \mathrm{L}^{-1}$ and $1 \mathrm{~g} \mathrm{~L}^{-1}$. The reaction temperature was $30{ }^{\circ} \mathrm{C}$. 198 